\title{
Recesión gingival: una revisión de su etiología, patogénesis y tratamiento
}

\section{Gingival recession: a review of its aetiology, pathogenesis and treatment}

\section{ARDILA IMEDINA CM*}

Ardila Medina CM. Recesión gingival: una revisión de su etiología, patogénesis y tratamiento. Av Periodon Implantol. 2009; 21 , 2: 35-43.

\section{RESUIMEN}

La recesión gingival describe la localización del margen gingival libre apical a la unión cemento esmalte; está asociada a estética indeseable, abrasión superficial radicular, sensibilidad y caries radicular. Reportes recientes indican que hay una prevalencia substancial en el aumento de las recesiones en diferentes poblaciones, incrementándose significativamente después de la quinta década. Uno de los objetivos de la terapia periodontal es corregir quirúrgicamente las recesiones, por esta razón, la eficacia y predecibilidad de algunas técnicas son consideraciones importantes para el paciente y el clínico. Una variedad de procedimientos quirúrgicos se han descrito como métodos efectivos para cubrir las superficies radiculares expuestas: injertos gingivales, pediculados, de tejido conectivo, plasma rico en plaquetas, regeneración tisular guiada y combinación de técnicas. El propósito de este artículo es presentar las causas que ocasionan la recesión, sus consideraciones histológicas, su clasificación, las indicaciones y contraindicaciones para el cubrimiento de las recesiones y la evaluación de las técnicas de tratamiento que se utilizan para cubrirlas.

PALABRAS CLAVE: Recesión gingival, lesiones mucogingival, tratamiento.

\section{SUMMARY}

The gingival recession describes to the location of the gingival margin free apical to the cement enamel junction; it is associate to aesthetic undesirable, superficial abrasion, sensitivity and radicular decay. Recent reports indicate significantly that there is a substantial prevalence in the increase of the recessions in different populations, being increased after the fifth decade. One of the objectives of the periodontal therapy is to correct the recessions surgically, therefore, the effectiveness and predecibilidad of some techniques are important considerations for the patient and the clinical one. A variety of surgical procedures has been described like effective methods to cover the exposed surfaces: gingivales grafts, pediculades, of conecttive weave, plasma rich in plaquets, tissue regeneration guided and combination of techniques. The aim of this article is to display the causes of the recession, their histologics considerations, their classification, the indications and contraindications for cover the recessions and the evaluation of the treatment techniques that are used to cover them.

KEY WORDS: Gingival recession, mucogingival injuries, treatment.

Fecha de recepción: 1 de septiembre de 2008.

Fecha de aceptación: 11 de septiembre de 2008. 


\section{INTRODUCCIÓN}

La recesión del tejido marginal gingival es definida como el desplazamiento del margen gingival apical a la unión cemento-esmalte con la exposición de la superficie radicular al ambiente oral (1). Otros autores la definen como la migración apical del margen gingival a lo largo de la superficie radicular (2). Carranza afirma que la recesión consiste en la exposición de la superficie radicular por una desviación apical en la posición de la encía (2). Para comprender cuál es su significado, es preciso diferenciar entre las posturas real y aparente de la encía. La posición real corresponde al nivel de la inserción epitelial en el diente, mientras que la aparente es la altura de la cresta del margen gingival, así la posición real de la encía, no su ubicación aparente, determina la gravedad de la recesión (2). La encía que presenta recesión se encuentra a menudo inflamada, pero puede ser normal excepto por su posición (2). La recesión se localiza en ocasiones en un diente en una sola superficie, en un grupo de dientes o puede generalizarse a través de la boca (3).

\section{EPIDEMIOLOGÍA Y ETIOLOGÍA DE LA RECESIÓN}

La recesión gingival aumenta con la edad. Su incidencia varía desde $8 \%$ en los niños hasta $100 \%$ luego de los 50 años de edad. (3). Informes recientes indican que hay una prevalencia substancial en el aumento de las recesiones en la población mundial, incrementándose significativamente después de la quinta década. Esto motiva a que ciertos investigadores supongan que la recesión es un proceso fisiológico vinculado con el envejecimiento( 3 ). Sin embargo, aún no se presentan pruebas convincentes sobre un cambio fisiológico de la inserción gingival. La migración apical gradual es, con mucha probabilidad, el resultado del efecto acumulativo de una afección patológica menor, los traumatismos menores directos y repetidos a la encía, o ambos. En poblaciones que presentan buenas medidas de higiene oral las recesiones marginales son mas frecuentes en las superficies bucales (4) y parece ser más común en dientes unirradiculares que en molares (5). En contraste las recesiones se encuentran cerca de todas las superficies dentarias en los pacientes comprometidos periodontalmente.

Al mismo tiempo, se ha enfocado la atención en los aspectos etiológicos, implicando muchos factores en la recesión gingival. Al menos tres tipos de recesiones gingivales pueden considerarse: recesiones asociadas a factores mecánicos, predominantemente técnicas de cepillado inadecuadas, frenillos traccionantes y factores iatrogénicos, (5) recesiones asociadas a lesiones inflamatorias inducidas por placa bacteriana, en casos de dehiscencias asociadas a periodonto delgado y en casos de dientes en malposición, (5) y recesiones asociadas a formas generalizadas de enfermedad periodontal destructiva (5).

Su etiología está determinada por una serie de factores predisponentes y desencadenantes (6). Los factores predisponentes pueden ser anatómicos y asociados a trauma oclusal. Los anatómicos incluyen escasa encía adherida, malposición dentaria y apiñamiento, prominencia radicular, dehiscencias óseas e inserción alta de frenillos que causan la tracción del margen gingival. Los asociados a trauma oclusal abarcan anatomía del tejido óseo alveolar circundante a la raíz del diente e intensidad y duración del trauma.

Los factores desencadenantes abarcan inflamación, cepillado traumático, laceración gingival, iatrogenia, márgenes subgingivales, diseño inadecuado de aparatología removible y movimientos ortodónticos no controlados. Si bien el cepillado de los dientes es importante para la salud de la encía, realizarlo defectuosamente puede causar recesión gingival, con tendencia a ser más frecuente y grave en los pacientes con encía comparativamente sana, poca placa bacteriana e higiene bucal adecuada (7). La posición de los dientes en el arco, (7) la angulación entre la raíz y el hueso y la curvatura mesiodistal de la superficie dental, (7) también afectan la tendencia a la recesión.

Varios aspectos de la recesión gingival la hacen relevante en términos clínicos. Las superficies radiculares expuestas son susceptibles a la caries. El desgaste del cemento exhibido por la recesión deja una superficie dentinaria subyacente muy sensible, en especial al tacto. La hiperemia pulpar y los síntomas concomitantes pueden aparecer también por la exposición de la superficie radicular (8). La recesión interproximal crea espacios donde la placa, los alimentos y las bacterias pueden acumularse.

Con base en observaciones clínicas sin ningún soporte metodológico, se consideraba que la encía queratinizada era necesaria para conservar la salud gingival, prevenir la recesión marginal gingival y mantener los niveles de inserción, ha sido cuestionada la necesidad para incrementar la cantidad de encía queratinizada, ya que se ha demostrado que mínimas cantidades son 
compatibles con condiciones periodontales saludables, siempre y cuando exista un adecuado control de placa bacteriana (6).

Este hallazgo fue corroborado histológicamente por Wennstrom (9), al demostrar que las zonas desprovistas de encía queratinizada respondían en igual forma a la agresión de la placa bacteriana que aquellas provistas con adecuadas bandas queratinizadas. Con esto se desvirtúo el argumento de la necesidad de la encía queratinizada para el mantenimiento de la salud gingival. Wennstron (9) aclaró, cómo dientes desprovistos de encía queratinizada en presencia de buena higiene oral, mantenían los niveles de inserción clínica sin presentar signos de retracción gingival durante largos períodos de tiempo, cuando se comparaban con dientes control con encía queratinizada. En la figura 1 se observa una marcada recesión gingival.

\section{CONSIDERACIONES HISTOLÓGICAS}

Siendo la inflamación una constante y sabiendo que el infiltrado inflamatorio se disemina en el tejido conjuntivo no solamente en sentido apical sino en todos los sentidos, las proyecciones epiteliales que se forman en el surco se pueden encontrar y fundir con aquellas del epitelio oral en las áreas donde la encía marginal es muy delgada. A medida que el tejido conjuntivo se destruye entre los dos epitelios puede ser ocupado en parte por el proliferante y emigrante epitelio del surco. Eventualmente cuando la encía es delgada puede ocurrir una anastomosis entre el epitelio del surco y el epitelio gingival oral como consecuencia de la proximidad entre ambos, por ende un área que originalmente estaba formada por tejido conjuntivo ahora se encuentra ocupada por tejido epitelial tornándose susceptible a degeneración (10).

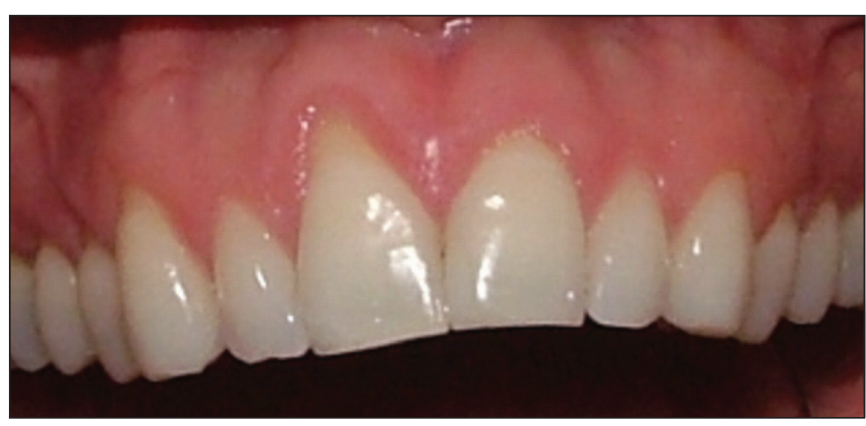

Fig. 1: Recesión gingival.

\section{CLASIFICACIÓN DE LASS RECESIONES GINGIVALES}

Para agrupar las recesiones gingivales existen dos clasificaciones reportadas en la literatura, la de Sullivan y Atkins y la de Miller. Sullivan y Atkins (11) clasificaron la recesión gingival en cuatro categorías morfológicas: superficial-estrecho, superficial-amplio, profundoestrecho y profundo-amplio.

Por otra parte, Miller (12) en 1985 determinó la siguiente categorización de las recesiones gingivales: Clase I, recesión de tejido marginal que no se extiende hasta la unión mucogingival, no hay pérdida de hueso ni de tejido blando en el área interdentaria. Clase II, consiste en una recesión de tejido marginal que se extiende apical a la línea mucogingival; no hay pérdida de tejido interproximal. Clase III, existe una retracción de tejido marginal gingival que se extiende apical a la unión mucogingival, en dientes con pérdida de altura del periodonto proximal. Clase IV, es una recesión de tejido marginal que se extiende apical a la línea mucogingival con pérdida ósea grave y de tejido blando a nivel interdental.

De acuerdo con el tipo de recesión se determina la técnica quirúrgica a realizar y el pronóstico de éxito. Se tiene en cuenta que se justifica realizar un procedimiento de cobertura de una recesión marginal, cuando ella ocasione problemas estéticos, de sensibilidad o de susceptibilidad a caries radicular. La cirugía mucogingival incluye varios procedimientos que ayudan a corregir defectos en cuanto a morfología, posición y dimensiones de la encía. Debido a que estos procedimientos tienen un enfoque estético el término cirugía plástica periodontal (13) ha sido propuesto como el más apropiado, siendo el cubrimiento radicular uno de los procedimientos estéticos que ha alcanzado mayor interés en la cirugía mucogingival.

\section{CONTRAINDICACIONES PARA CUBRIR RECESIONES GINGIVALES}

Es un reto discutir acerca de las contraindicaciones para cubrir recesiones gingivales ya que la línea divisoria entre indicaciones y contraindicaciones no está claramente definida.

Antes de tratar cualquier condición periodontal, incluyendo recesiones, se deben identificar los factores de riesgo responsables de ella. Los factores de riesgo están subdivididos en aquellos que pueden ser modi- 
ficados o corregidos y en aquellos que no (14). Los factores que no pueden ser modificados o corregidos pueden ser considerados como una contraindicación para técnicas de cubrimiento de recesiones (14).

Un factor de riesgo que usualmente no puede ser modificado es la pérdida de hueso interproximal. Millar (12) en su clasificación de las recesiones gingivales, toma esto en cuenta, determinando que la clase III y IV no pueden ser cubiertas y su pronóstico es malo. Sin embargo, se han reportado casos en los cuales sitios con pérdida ósea interproximal han sido tratados exitosamente, pero infortunadamente no hay estudios controlados de estos procedimientos.

El tabaco es considerado como el mayor factor de riesgo que puede contribuir al fracaso de los procedimientos quirúrgicos mucogingivales. El mecanismo preciso por el cual el tabaco interfiere con la cicatrización no es completamente entendido, debido al hecho de que son cientos de toxinas las que contiene, muchas de las cuales no han sido identificadas, y mucho menos evaluadas por su efecto en la cicatrización periodontal (15).

La higiene oral es otro factor de riesgo que puede ser modificado. O'Leary y cols. mostraron que los pacientes con bajos índices de placa bacteriana presentaron mayor cantidad de recesiones (16). Las técnicas inadecuadas de higiene oral causan mas recesiones que requieren correcciones quirúrgicas. Solo si los pacientes pueden ser exitosamente reeducados se evitará una cirugía mucogingival.

Malos hábitos como el uso inapropiado de elementos en la encía, palillos o posicionamiento de las uñas, deben ser corregidos para evitar las recesiones y su posible corrección quirúrgica.

Las características anatómicas pueden contribuir a la recesión gingival, especialmente si el periodonto es delgado. Esto ocurre con frecuencia en dientes en malposición, sin embargo estos problemas no son considerados como significativos, ya que las técnicas quirúrgicas modernas proveen al clínico la posibilidad de ser tratados con éxito.

\section{TÉCNICAS PARA CUBRIR RECESIONES GINGIVALES}

Diferentes autores han llevado a cabo ensayos clínicos con el fin de evaluar el éxito de los procedimientos quirúrgicos para cubrir recesiones (15). Miller (13) reportó un injerto gingival libre predecible para cubrir recesiones gingivales. Langer y Langer (17) decribieron una técnica empleando un injerto de tejido conectivo subepitelial. Raetzke (18) describió la técnica en bolsillo. Nelson (19), el subpediculado. Harris (20) el doblemente pediculado. Allen (21) el procedimiento en túnel y Bernimoulin y cols. (22) la técnica del colgajo posicionado coronalmente que actualmente se utiliza para cubrir injertos subepiteliales de tejido conectivo conocida también como técnica bilaminar. Estos procedimientos tienen diferentes niveles de éxito cuando se utilizan para ganar cubrimiento de la recesión y encía queratinizada.

\section{Injerto epitelizado libre}

La técnica descrita originalmente por Sullivan y Atkins (11) abarca la preparación de un lecho receptor usando disección supraperióstica para remover epitelio y tejido conectivo. Algunas de las áreas donantes comunes incluyen rebordes edéntulos, zonas retromolares y tejido gingival palatino. Dorfman y cols. (23) realizaron un estudio de seguimiento con el fin de comparar sitios donde se ubicaron injertos epitelizados con sitios control donde no se ubicó ningún injerto. Estos autores reportaron que niveles bajos de placa bacteriana eran más importantes que la amplitud de la encía queratinizada para evitar la aparición de una recesión. Además encontraron que el injerto epitelizado es una técnica predecible para aumentar encía queratinizada.

Holbrook y Ochsenbein (24) concluyeron en un reporte utilizando injertos epitelizados, que el cubrimiento de las recesiones marginales eran del 95,5\% si su dimensión correspondía a menos de $3 \mathrm{~mm}$, del $80,6 \%$ si las retracciones se encontraban entre 3 y $5 \mathrm{~mm}$ y del $76,6 \%$ si eran mayores a $5 \mathrm{~mm}$. En otro estudio, Miller (13) empleando la misma técnica en 100 sitios, pero combinándola con ácido cítrico encontró $100 \%$ de cubrimiento radicular en recesiones Clase I y $88 \%$ en defectos clase II. Otros autores reportan cubrimientos radiculares de solamente $36 \%$ y $44 \%$ utilizando injertos epitelizados.

\section{Injerto libre de tejido conectivo}

El injerto libre de tejido conjuntivo tiene las mismas indicaciones de la técnica anterior y sus resultados presentan una variabilidad predecible como ocurre con el injerto gingival libre. Presenta algunas ventajas 
con relación al injerto epitelizado pues el postoperatorio es menos incómodo principalmente por el hecho de permitir una cicatrización por primera intención en la región donante y el resultado es más estético debido a una mayor uniformidad en cuanto al color con relación a los tejidos adyacentes al área receptora. Langer y Langer (17), en un estudio a 4 años, mostraron un cubrimiento radicular de 2 a $6 \mathrm{~mm}$ en $56 \mathrm{ca}$ sos. Raetzke (18) describió una técnica en sobre para obtener cubrimiento radicular usando injertos de tejido conectivo y encontró un cubrimiento del $80 \%$ de las superficies radiculares expuestas y Allen (21), utilizando esta misma técnica, logró un éxito del $84 \%$. Jahnke y cols. (25) compararon los resultados obtenidos al realizar injertos epitelizados libres e injertos de tejido conectivo y encontraron un cubrimiento radicular del $43 \%$ para los primeros y $80 \%$ para los de tejido conectivo. En un estudio similar, seguido durante 5 años y realizado por Paolantonio y cols., (26) observaron que el injerto de tejido conectivo presentó un $85 \%$ de éxito comparado con un $53 \%$ del injerto epitelizado libre. Esto concluye que el injerto de tejido conectivo es un procedimiento más predecible para cubrir recesiones gingivales. En la figura 2 se observa la técnica bilaminar (TB) que combina un injerto conectivo ubicado sobre la superficie radicular expuesta cubierto por un colgajo desplazado coronalmente.

\section{Colgajo desplazado lateralmente}

Esta técnica descrita por Grupe y Warren (27) es también muy predecible, menos dolorosa y relativamente fácil de realizar. El colgajo desplazado lateralmente presenta una ventaja debido a que el área donante es próxima y adyacente al área receptora, evitando la necesidad de dos áreas quirúrgicas, pero requiere como área donante un área edéntula significativa adyacente a aquella que presenta el problema mucogingi-

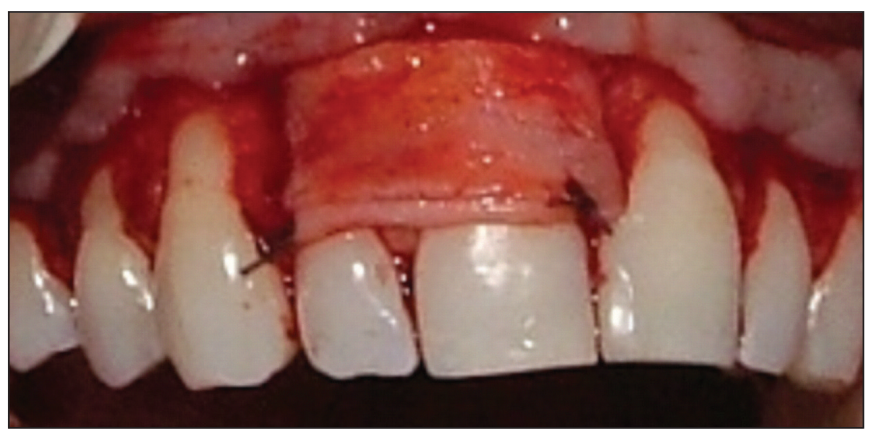

Fig. 2: Técnica bilaminar. val. Cohen y Ross (28) propusieron un colgajo reposicionado de doble papila para cubrir defectos en los cuales está presente una insuficiente cantidad de encía. Las papilas de cada lado del diente son levantadas y rotadas sobre el aspecto medial facial del diente receptor y son suturadas. La única ventaja de esta técnica es el doble suministro sanguíneo y que se denuda únicamente el hueso interproximal. Las desventajas incluyen tracción exagerada de la sutura y desgarramiento de la papila gingival.

\section{Colgajo desplazado coronalmente}

Esta técnica, inicialmente descrita por Bernimoulin y cols. (22) y posteriormente modificada por Liu y Solt (29), tiene como indicación el tratamiento de las recesiones gingivales localizadas cuando no existe área edéntula donante adyacente al área de la retracción. Consiste en colocar inicialmente un injerto gingival libre, esperando un período de cicatrización de 6 semanas para posteriormente elevar un colgajo y desplazarlo coronalmente. Méndes y cols. (30), empleando esta técnica, mostraron una cobertura media de $72,17 \%$ en casos de retracciones periodontales extensas. Allen (21) y Millar (12) lograron un cubrimiento radicular del $84 \%$ y Harris (20) mostró $98 \%$ de éxito en el cubrimiento de recesiones clase I de Miller usando colgajos desplazados coronalmente.

En un estudio prospectivo realizado durante seis meses (31), con el fin de comparar colgajos posicionados coronalmente con colgajos desplazados lateralmente, para el tratamiento de recesiones gingivales localizadas, se encontraron resultados satisfactorios, aunque no se presentaron diferencias en cuanto a cantidad de cubrimiento de la recesión, profundidad de sondaje y ganancia de encía adherida.

\section{Colgajo semilunar desplazado coronalmente}

Esta técnica puede ser considerada una variación de la anterior y fue descrita por Tarnow (32) En ella es necesaria la presencia de una buena banda de encía queratinizada, siendo ideal en casos de retracciones poco extensas.

\section{Aloinjerto de matriz dérmica acelular (AMDA)}

Este injerto originalmente utilizado para cubrir quemaduras de gran espesor ha sido introducido como 
alternativa para lograr incremento en la amplitud de encía queratinizada. Es un aloinjerto, seco congelado, libre de células con una matriz extracelular de fibras colágena y elásticas. Este material alogénico es derivado de la piel humana y posteriormente tratado para remover antigenicidad. La integridad ultraestructural del AMDA es mantenida, evitando una inducción de la respuesta inflamatoria (33). Estudios clínicos e in vitro sugieren que repara por repoblación y revascularización mejor que a través de un proceso de granulación que madura hasta cicatrizar (34). Tiene una polaridad por medio de la cual uno de los lados del material tiene una lámina basal para el crecimiento de células epiteliales y el otro lado tiene una matriz dérmica porosa subyacente, permitiendo el crecimiento de fibroblastos y células angiogénicas (34). Tiene características de manipulación que permiten una buena aplicación y estabilización en los tejidos gingivales (34).

Uno de los problemas con el cubrimiento radicular a partir de injertos de tejido conectivo es la falta de disponibilidad suficiente de suministro de este tipo de tejido en caso de grandes y múltiples recesiones gingivales. Utilizar el paladar como área donante puede estar asociado con molestias postoperatorias y si además el paciente presenta un paladar poco profundo o tisularmente delgado existe dificultad para tomar suficiente tejido donante de un solo sitio. El AMDA provee un suministro ilimitado de material de injerto permitiendo cubrir recesiones en todo un sextante o cuadrante eliminando además el molesto postoperatorio ocasionado por la herida en el paladar cuando se toman injertos de tejido conectivo. En la figura 3 se observa una matriz dérmica acelular sobre una superficie radicular expuesta.

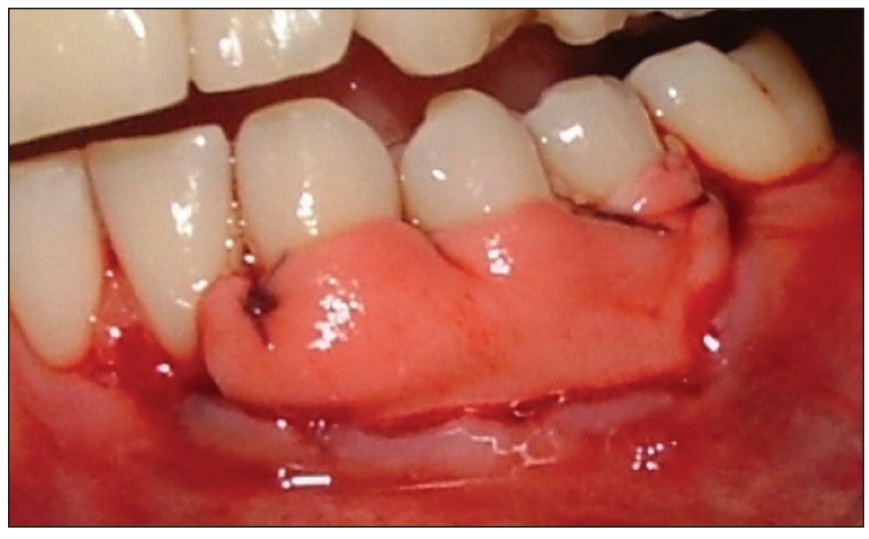

Fig. 3: Matriz dérmica acelular.
En un estudio experimental para evaluar el AMDA cubierto con un colgajo desplazado coronalmente y una técnica bilaminar (TB) se encontró que fueron similarmente exitosas para cubrir las recesiones gingivales, sin embargo el grupo TB obtuvo un incremento significativamente mayor en la amplitud de encía queratinizada mostrando además una cicatrización más rápida (35). Una investigación realizada por Tal y cols. con el fin de evaluar TB y AMDA cubierto por un colgajo desplazado coronalmente en recesiones mayores de cuatro milímetros, reportó resultados similares al estudio anterior en cuanto a capacidad de cubrir las recesiones presentando también una mayor banda de encía queratinizada en la técnica bilaminar (36). Concluyen también que cubrir el AMDA con un colgajo dividido desplazado coronalmente requiere mayor esfuerzo pues su habilidad para revascularizarse depende del íntimo contacto con tejido vital. En otra investigación realizada con el fin de comparar capacidad de cubrimiento radicular lograda por el AMDA cubierto con colgajo desplazado coronalmente y la TB concluyó que no existían diferencias clínicas ni estadísticamente significativas entre ellas (37). Andrade y cols. (38), empleando el AMDA en dos grupos experimentales, compararon incisiones verticales en el colgajo desplazado coronalmente frente a un colgajo sin relajantes, concluyendo que no se observaron diferencias significativas en el cubrimiento de las recesiones al comparar las dos técnicas quirúrgicas. Finalmente, un estudio no reportó diferencias significativas en el promedio de cubrimiento radicular obtenido $(96,2 \%$ TB y 95,8\% AMDA). Se observó una reducción estadísticamente significativa en la profundidad de sondaje (1,2 mm TB y 0,7 mm AMDA) y un incremento en la amplitud de la encía queratinizada ( $2 \mathrm{~mm}$ TB y $1,2 \mathrm{~mm}$ AMDA) (39). Las conclusiones de este estudio son confirmadas por otras investigaciones realizadas en la última década (40-42). La tabla l presenta el porcentaje de cubrimiento radicular cuando se compara el AMDA y la TB en diferentes estudios.

\section{Combinación de técnicas}

Muchos clínicos han intentado combinar diferentes técnicas quirúrgicas con el fin de incrementar la posibilidad de éxito en el cubrimiento radicular, pero sin lograr diferencias clínicas evidentes científicamente. Nelson (19) utilizó injertos de tejido conectivo combinado con un injerto pediculado doble. Harris a su vez modificó la técnica de Nelson (43), utilizando un injerto pediculado dividido seccionado para cubrir injertos de tejido conectivo. 


\begin{tabular}{|c|c|c|c|}
\hline \multicolumn{4}{|c|}{$\begin{array}{l}\text { TABLA 1.- PORCENTAJE DE } \\
\text { CUBRIMIENTO RADICULAR } \\
\text { COMPARANDO AMMA Y TB }\end{array}$} \\
\hline \begin{tabular}{|l} 
Procedimiento \\
periodontal
\end{tabular} & $\begin{array}{l}\text { Cubrimiento } \\
\text { radicular (\%) }\end{array}$ & Seguimiento & Autor \\
\hline $\begin{array}{l}\text { AMDA } \\
\text { TB }\end{array}$ & $\begin{array}{l}83,33 \\
88,8\end{array}$ & 1 año & (35) \\
\hline $\begin{array}{l}\text { AMDA } \\
\text { TB }\end{array}$ & $\begin{array}{l}89,1 \\
88,7\end{array}$ & 1 año & (36) \\
\hline \begin{tabular}{|l|} 
AMDA \\
TB
\end{tabular} & $\begin{array}{l}65,9 \\
74,1\end{array}$ & 6 meses & (37) \\
\hline $\begin{array}{l}\text { AMDA } \\
\text { TB }\end{array}$ & $\begin{array}{l}65,01 \\
61,95\end{array}$ & 6 meses & $(42)$ \\
\hline $\begin{array}{l}\text { AMDA } \\
\text { TB }\end{array}$ & $\begin{array}{l}96,2 \\
95,8\end{array}$ & 3 meses & $(41)$ \\
\hline
\end{tabular}

\section{Regeneración tisular guiada (RTG)}

El uso de técnicas de regeneración tisular guiada ha sido sugerido para el tratamiento de recesiones gingivales. Se han utilizado membranas reabsorbibles, no reabsorbibles, no reabsorbibles con esqueleto de titanio, combinación de estas con tejidos conectivos, derivados de la matriz del esmalte, colgajos posicionados coronalmente, demostrando resultados controvertidos (44). Trombelli y cols. (45) mostraron una diferencia significativa en el promedio de cubrimiento radicular cuando compararon RTG mediante membranas bioabsorbible ( $48 \%$ de cubrimiento) con injertos de tejido conectivo ( $81 \%$ de cubrimiento). En otro estudio se comparó la RTG con una técnica bilaminar y los autores concluyeron que el porcentaje de cubrimiento radicular utilizando RTG es del $50 \%$ mientras que para la técnica bilaminar es del $82 \%$ (46). Harris (47), soporta esta misma conclusión, reportando que el $92 \%$ en promedio obtenido por RTG en los primeros seis meses, se reduce a un 58\% después de una evaluación realizada a los 25 meses. Una revisión sistemática divulgada en 2008 , teniendo como referencia 568 publicaciones en donde se comparan la regeneración tisular guiada, el AMDA y la TB concluye que esta última debe ser considerada el estándar de oro cuando se desea cubrir recesiones gingivales. Sin embargo, no se observaron diferencias estadísticamente significativas en cuanto a los niveles de inserción clínica al comparar las tres técnicas (48). Estos resultados son corroborados por otra revisión sistemática realizada por Oates y cols. recientemente (49).

\section{CONCLUSIONES}

1. El cubrimiento de las recesiones gingivales puede ser logrado con varias técnicas quirúrgicas.

2. Los injertos epitelizados reportan principalmente aumento en la amplitud de la encía queratinizada, pero su aspecto estético no es muy favorable.

3. Los injertos tomados de la zona palatina presentan un postoperatorio molesto para el paciente, especialmente los epitelizados.

4. Los colgajos desplazados lateralmente y de doble papila son técnicas que requieren indicaciones muy precisas, además de gran habilidad del clínico para realizarlas.

5. La combinación de injertos de tejido conectivo y colgajos desplazados coronalmente (TB) demuestran los mayores porcentajes de éxito.

6. El AMDA y la RTG son procedimientos que también pueden ser empleados para tratar recesiones marginales, especialmente en aquellos pacientes que rechazan la obtención de injertos a partir del paladar o en aquellos con recesiones múltiples.

\section{BIBLIOGRAFÍA}

1. The American Academy of Periodontology. Glossary of Periodontal Terms, 4th ed. Chicago:The American Academy of Periodontology; 2001:44.

2. Carranza F, Newman M. Clinical Periodontology. 9 ed. 2001.

3. Woofter C. The prevalence and etiology of gingival recession. Periodontal Abstr 1969;17:45-50.

4. Serino G, Wennstrom JL, Undhe J, Eneroth L. The prevalence and distribution of gingival recession in subjects with a high standard of oral hygiene. J Clin Periodontol 1994;2:57-63.

5. Loe, H., Anerud, A., Boysen, H. The natural history of periodontal disease in man: prevalence, severity, extent of gingival recession. J Periodontol 1992;63:489-95. 
6. Ferro MB, Gómez M. Fundamentos de la Odontología. Periodoncia. 2000.

7. Gorman NJ. Prevalence and etiology of gingival recession. J Periodontol 1967:38;316-20.

8. Merritt AA. Hyperemia of the dental pulp caused by gingival recession. J Periodontol 1933: 4:30.

9. Wennstrom J. Lack of association between width of attached gingival and development of softt tissue recession a 5 years longitudinal study. J Clin Periodontol 1987:14; 181-4.

10. Novaes AB, Kon S, Ruben ME, Goldman HMG, Novaes Jr AB. The development of the periodontal cleft. J Periodontol 1975; 46: 701-9.

11. Sullivan HC, Atkins JC. Free autogenous gingival grafts 3. Utilization of grafts in the treatment of gingival recession. Periodontics 1968: 6;152-60.

12. Miller PD Jr. A classification of marginal tissue recession. Int J Periodontics Restorative Dent 1985; 5:8-13.

13. Miller PD. Root coverage grafting for regeneration and aesthetics. Periodontol 2000. 1993; 1: 118-127.

14. Gray J.When not to perform root coverage procedures.J Periodontol 2000; 71: 1048-50.

15. Trombelli L, Scabbia A. Healing response of gingival recession defects following guided tissue regeneration procedures in smokers and non-smokers. J Clin Periodontol 1997; 24: 529-33.

16. O'Leary TJ, Drake RB, Crump PP, Allen MF. The incidence of recession in young males: A further study. J Periodontol 1971;42:264-67.

17. Langer S, Langer L. Subepithelial connective tissue graft technique for root coverage. J Periodontol 1985; 56: 715-20.

18. Raetzke PB. Covering localized areas of root exposure employing the "envelope" technique. J Periodontol 1985; 56: 397-402.

19. Nelson S. The subpedicle connective tissue graft: $A$ bilaminar reconstructive procedure for the coverage of denuded root surfaces. J Periodontol 1987; 58: 95102 .
20. Harris RJ. The connective tissue with partial thickness double pedicle graft: The results of 100 consecutively treated defects. J Periodontol 1994; 65: 448-61.

21. Allen AL. Use of the supraperiosteal envelope in soft tissue grafting for root coverage. I. Rationale and technique. Int J Periodontics Restorative Dent 1994; 14:216-27.

22. Bernimoulin JP, Luscher B, Muhlemann HR. Coronally repositioned periodontal flap. Clinical evaluation after 1 year. J Clin Períodontol 1975; 2:1-13.

23. Dorfman HS, Kennedy JE, Bird WC. Longitudinal evaluation of free autogeous gingival grafts. A four year report. J Periodontol 1982; 53:349-52.

24. Holbrook T, Ochsenbein, C. Complete coverage of the derived root surface with a one stage gingival graft. Int J Periodontics Restorative Dent 1983;3:9-27.

25. Jahnke PV, Sandifer JB, Gher ME, Gray JL, Richardson AC. Thick free gingival and connective tissue autografts for root coverage. J Periodontol 1993;64:315-22.

26. Paolantonio M, di Murro C, Cattabríga A, Cattabriga M. Subpedicle connective tissue graft versus free gingival graft in the coverage of exposed root surfaces. A 5-year clinical study. J Clin Periodontol 1997;24:51-6.

27. Grupe J, Warren, R. Repair of gingival defects by a sliding flap operation. J Periodontol 1956; 27: 290-5.

28. Cohen DW, Ross SE. The double papillae repositioned flap in periodontal therapy. J Periodontol 1968;39:6570.

29. Liu WJ, Solt, CN. A surgical procedure for the treatment of localized gingival recession in conjunction with root surface citric acid conditioning. J. Periodontol 1980; 51:500-9.

30. Mendes DNRM, Novaes Jr AB, Novaes AB. Root coverage of large localized gingival recession: A biometric study. Braz Dent J 1997;8:113-20.

31. Caffesse RG, Guinard EA. Treatment of localized gingival recession part IV: results after 3 years. J Periodontol 1978;49:457-61.

32. Tarnow, DP. Semilunar coronally repositioned flap. J Clin Periodontol 1986;13:182-85. 
33. Wainwright D, Madden M, Luteman A, et al. Clinical evaluation of an acellular allograft dermal matrix in full thickness burns. J Burn Care Rehabil 1996; 17:124-26.

34. Reagan BL, Madden MR, Huo J, Mathwich M, StaianoCoico L. Analysis of cellular and decellular allogenic dermal grafts for the treatment of full-thickness wounds in a porcine model. J Trauma 1997;43:458-66.

35. Paolantonio M, Dolci M, Esposito P, D'Archivio D, Lisanti L, Di Luccio A et al. Subpedicle acellular dermal matrix graft and autogenous connective tissue graft in the treatment of gingival recessions: A comparative 1 year clinical study. J Periodontol 2002;73:1299-307.

36. Tal H, Moses O, Zohar R, Meir H, Nemcovsky C. Root coverage of advanced gingival recession: A comparative study between acellular dermal matrix allograft and subepithelial connective tissue grafts. J Periodontol 2002;73:1405-11.

37. Aichelmann-Reidy ME, Yukna RA, Evans GH, Nasr HF, Mayer ET. Clinical evaluation of a acellular allograft dermis for the treatment of human gingival recession. J Periodontol 2001;72:998-1005.

38. Andrade PF, Felipe ME, Novaes AB Jr, Souza SL, Taba M Jr, Palioto DB, Grisi MF. Comparison between two surgical techniques for root coverage with an acellular dermal matrix graft. J Clin Periodontol. 2008; 35:263-9.

39. Muller HP, Eger T, Shorb A. Gingival dimensions after root coverage with free connective tissue grafts. J Clin Periodontol 1998;25:424-30.

40. Rahmani ME, Lades MA. Comparative clinical evaluation of acellular dermal matrix allograft and connective tissue graft for the treatment of gingival recession. J Contemp Dent Pract. 2006(1);7:63-70.

41. Harris RJ. A comparative study of root coverage obtained with an acellular dermal matrix versus a connective tissue graft: results of 107 recessions defect in 50 consecutively treated patients. In J Periodontics Restorative Dent 2000; 20: 51-9.
42. Novaes AB Jr, Grisi D, Molina G, Souza S, Taba M, Grisi M. Comparative 6 month clinical study of a subepithelial connective tissue graft and acellular dermal matrix allograft for the treatment of gingival recession. J Periodontol 2001; 72: 1477-84.

43. Harris RJ. The connective tissue and partial thickness double pedicle graft: A predictable method of obtaining root coverage. J Periodontol 1992; 63:477-86.

44. Ardila CM. Regeneración Tisular Guiada: Bases biológicas y Clínicas. Rev Federación Odontológica Colombiana 2003;65:37-50.

45. Trombelli L, Scabbia A, Tatakis DN, Calura G. Subpedicle connective tissue graft versus guided tissue regeneration with bioabsorbable membrane in the treatment of human gingival recession defects. J Periodontol 1998;69:1271-7.

46. Muller HP, Stahl M, Eger T. Failure of root coverage of shallow gingival recessions employing GTR and bioreabsorbable membrane. Int J Periodontics Restorative Dent 2001;21:171-81.

47. Harris RJ. GTR for root coverage: a long-term follow-up. Int J Periodontics Restorative Dent 2002;22:55-61.

48. Chambrone L, Chambrone D, Pustiglioni FE, Chambrone LA, Lima LA. Can subepithelial connective tissue grafts be considered the gold standard procedure in the treatment of Miller Class I and II recession-type defects? J Dent. 2008;36:659-71.

49. Oates TW, Robinson M, Gunsolley JC. Surgical therapies for the treatment of gingival recession. A systematic review. Ann Periodontol. 2003;8:303-20.

\section{CORRESPONDENCIA}

Carlos Martín Ardila Medina Carrera 47 No. 20 sur 46 Envigado Antioquia 57(4) 3348122

cmartin@odontologia.udea.edu.co 